\title{
Journal of Heminthology
}

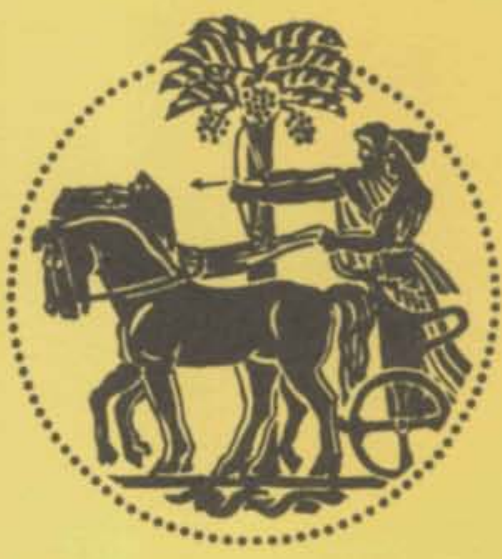




\section{JOURNAL OF HELMINTHOLOGY}

(Founded by R. T. Leiper in 1923 and edited from 1946-72 by J. J. C. Buckley and from 1972-80 by $R$. Muller and from 1980-86 by $S$. Willmott)

EDITORS: Dr. Ralph Muller and Dr. Lotfi F. Khalil

Editorial Assistant: Hilary White

International Institute of Parasitology,

395A Hatfield Road,

St Albans, Herts AL4 0XQ, England.

Subscription enquiries should be sent to:

Bureau of Hygiene \& Tropical Diseases,

Keppel Street,

London WC1E 7HT, England.

Advertisement enquiries should be sent to:

Mrs D. Curtis,

P.J.A.R. Ltd.,

The Mill,

East Row,

Chichester,

West Sussex,

PO19 1PG, England.

Published in 4 parts per year.

Back volumes should be ordered from Wm. Dawson \& Sons Ltd., (Back Issues Dept.), Cannon House, Folkestone, Kent CT195EE, England. Prices on application. 